\title{
Synthesis of conical Co-Fe alloys structures obtained with crystal modifier in superimposed magnetic field
}

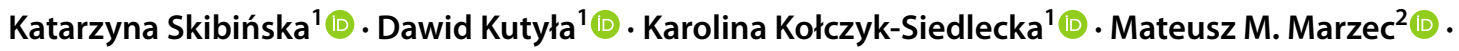 \\ Piotr Żabiński ${ }^{1} \oplus \cdot$ Remigiusz Kowalik $^{1}[0$
}

Received: 10 June 2021 / Revised: 25 August 2021 / Accepted: 30 September 2021 / Published online: 11 October 2021

(c) The Author(s) 2021

\begin{abstract}
The addition of crystal modifier to electrolyte used during electrodeposition of metals and alloys allows obtaining conical structures without using any template. This method is fast and ensures covering large areas during one single electrodeposition process. In this work, Co-Fe cones were obtained by one-step method with ammonium chloride as a crystal modifier. The influence of electrodeposition parameters and electrolyte compositions were investigated. Electrodeposition conditions (duration, electrolyte temperature, and addition of $\mathrm{NH}_{4} \mathrm{Cl}$ ), which allow obtaining the most uniform conical structures, were applied during sample fabrication in the magnetic field. The influence of its value and direction on the quality and compositions of obtained alloys was investigated using Scanning Electron Microscope (SEM) photos. To check if there is any change in the sample crystal system, the X-Ray Diffraction (XRD) analysis was performed. To confirm the synthesis of $\mathrm{Co}-\mathrm{Fe}$ cones, they were analyzed using the X-ray photoelectron Spectroscopy (XPS) method.
\end{abstract}

Keywords Co-Fe alloys $\cdot$ Crystal modifier $\cdot$ Conical structures $\cdot$ Magnetic field $\cdot$ Free-standing structures

\section{Introduction}

The Co-Fe alloys are the alloys of the two ferromagnetic metals. Due to their excellent magnetic properties [1], they are widely used in fields connected with electronic and magnetic devices [2]. They are also catalysts [3]. One of the standard methods of Co-Fe alloys synthesis is electrodeposition [4]. This well-investigated method is a low-cost and simple one. It allows the production of the Co-Fe alloy in anodic alumina oxide templates [6-8] and silicon wafers [9] as well. Co-Fe alloys are also characterized by good resistance to corrosion [10].

The one-step method connects the advantages of the electrodeposition process with the control of the structure shapes. It is caused by the presence of a crystal modifier that promotes specific directions of growth. This component is

Katarzyna Skibińska

kskib@agh.edu.pl

1 Faculty of Non-Ferrous Metals, AGH University of Science and Technology, A. Mickiewicza 30, 30-059 Krakow, Poland

2 Academic Centre for Materials and Nanotechnology, AGH University of Science and Technology, A. Mickiewicza 30, 30-059 Krakow, Poland also called a capping agent. Variously shaped structures of metals and alloys can be obtained during a single electrodeposition process. Unfortunately, the structure's size cannot be easily controlled. It requires investigation of suitable parameters depending on a desirable range of their size. However, they are usually on a micro-scale. For example, to produce cones, $\mathrm{NH}_{4} \mathrm{Cl}$ [11] or $\mathrm{CaCl}_{2} \bullet 2 \mathrm{H} 2 \mathrm{O}$ [12] can be added as the crystal modifier. The specific process conditions have to be applied. Co-Fe alloy cones could be used as the catalyst in a water-splitting reaction. The fabrication of conical, sharp-ended structures could also ensure superhydrophobic properties of layers [13]. To call the surface superhydrophobic one, the water contact angle has to be larger than $150^{\circ}$. This ability allows applying these materials in many fields, e.g. corrosion resistance [14] or antibacterial materials [15].

The use of an external magnetic field during the electrodeposition process allows the properties of the obtained coatings to be modified. This is due to the influence of the magnetic field on mass transport, reaction kinetics or the metal deposition process. This phenomenon is known as the magnetohydrodynamic effect (MHD) [16].

The Lorentz force is the force responsible for the transport of charged molecules. It can be defined as (Eq. 1): 
$\vec{F}=q(\vec{E}+\vec{v} \times \vec{B})$,

where $q$ is a charge on the particle, and $v$ is its velocity, $E$ is connected with the electric field strength vector, and $B$ is the magnetic field flux density vector [17]. This force influences the transport of the electrolyte at the electrode surface. This reduces the thickness of the Nernst layer.

In terms of magnetic properties, metals are divided into para-, dia- and ferromagnetic. Depending on the properties of the ions of these metals, the magnetic field may have a different effect on the obtained coatings. Cobalt and iron are ferromagnetic metals, which alloys are widely applied in magnetic devices and microelectromechanical systems called MEMS [18]. The application of a magnetic field and its direction strongly influence the electrodeposition process [19]. It is connected with the mentioned before MHD effect. The parallel-to electrode magnetic field causes obtaining denser and more homogenous coating than one deposited without applied magnetic field. The electrodeposition rates increase with the magnetic flux density. In the case of the perpendicular-to-electrode magnetic field, there is no significant influence on these rates. It is expected due to negligible Lorentz force. The coatings are more diverse as well. Moreover, the magnetic field perpendicular to applied current density causes decreasing in coatings thickness due to the enhancing of hydrogen evolution [20]. There are several works describing the electrodeposition of $\mathrm{Co}-\mathrm{Fe}$ coatings in the magnetic field [21-23]. In regard to the magnetic properties of these metals, there is a tendency to electrodeposit in areas with a high magnetic field gradient [22]. Due to described MHD effect, the change of $\mathrm{pH}$ near the electrode surface is also less extend in the superimposed magnetic field than without it [23]. However, no influence of the flux density and orientation of the applied magnetic field on the chemical composition of Co-Fe alloys was observed [21].

In this work, the $\mathrm{Co}-\mathrm{Fe}$ alloy cones were successfully synthesized using the one-step method from an electrolyte containing $\mathrm{NH}_{4} \mathrm{Cl}$ as a crystal modifier. The attempt to use $\mathrm{NaCl}$ as the capping agent was made. There is no previous research in the literature connected with obtaining this alloy using the one-step method. The influence of the capping agent, electrolyte temperature and deposition time was checked using Scanning Electron Microscope (SEM) photos. Due to the ferromagnetic properties of cobalt and iron, the magnetic field with different intensities and directions was applied during electrodeposition as well. It ensured obtaining layers characterized by different shape of structures and alloy compositions. Samples were analyzed using Scanning Electron Microscope (SEM), Energy Dispersive Spectroscopy (EDS), X-Ray Photoelectron Spectroscopy (XPS) and X-Ray Diffraction (XRD) methods.
Table 1 Chemical composition of used electrolytes [19]

\begin{tabular}{lccc}
\hline Concentration & Electrolyte A & Electrolyte B & Electrolyte C \\
\hline $\mathrm{CoSO}_{4}[\mathrm{mM}]$ & 6.5 & 6.5 & 6.5 \\
$\mathrm{FeSO}_{4}[\mathrm{mM}]$ & 3.3 & 6.5 & 10.0 \\
$\mathrm{Na}_{2} \mathrm{SO}_{4}[\mathrm{mM}]$ & 96.8 & 93.5 & 90.0 \\
$\mathrm{H}_{3} \mathrm{BO}_{3}[\mathrm{M}]$ & 0.4 & 0.4 & 0.4 \\
\hline
\end{tabular}

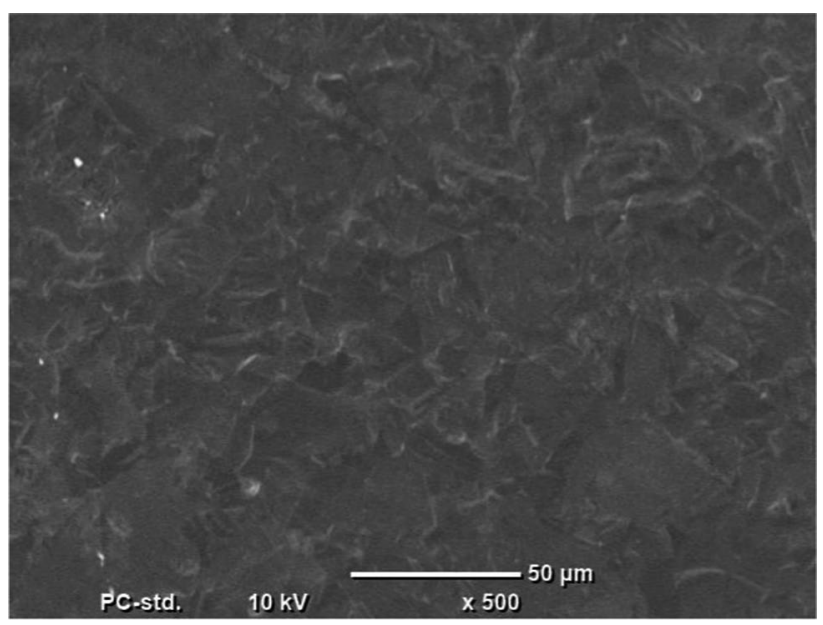

Fig. 1 Top-view of the $\mathrm{Cu}$ substrate after chemical polishing (magnification: $\times 500$ )

\section{Materials and methods}

Conical Co-Fe alloy deposits were electrodeposited onto $\mathrm{Cu}$ foil from the three different electrolytes containing $\mathrm{CoSO}_{4}, \mathrm{FeSO}_{4}, \mathrm{NaSO}_{4}, \mathrm{H}_{3} \mathrm{BO}_{3}$, and $\mathrm{NH}_{4} \mathrm{Cl}$ as a crystal modifier. Their compositions are shown in Table 1.

As a based electrolyte, the $\mathrm{B}$ one was used due to the equal concentration of $\mathrm{CoSO}_{4}$ and $\mathrm{FeSO}_{4}$. In all cases, the bath $\mathrm{pH}$ value was adjusted to 3 with $\mathrm{H}_{2} \mathrm{SO}_{4}$. The copper substrate was polished by immersion into a mixture of acids: $\mathrm{H}_{3} \mathrm{PO}_{4}, \mathrm{CH}_{3} \mathrm{COOH}$, and $\mathrm{HNO}_{3}$ (volume ratio 1:1:1) at $70{ }^{\circ} \mathrm{C}$ for $10 \mathrm{~s}$. Its surface was $2.8 \mathrm{~cm}^{2}$. The top view of this surface is shown in Fig. 1.

The electrodeposition process was carried out galvanostatically in a two-electrodes cell with Pt foil as an anode and $\mathrm{Cu}$ foil as a cathode. The value of applied current density was $20 \mathrm{~mA} / \mathrm{cm}^{2}$. All used reagents were characterized by analytical purity $(\mathrm{POCH})$. Deionized water was used for preparing the solutions. The influence of the electrodeposition time, the amount of crystal modifier, and electrolyte temperature on the morphology of the structures was determined. The sufficient electrodeposition parameters were compared in the case of using different electrolytes. Then, the superimposed magnetic field was applied using 
the electromagnet LakeShore (Model 642). The intensity value was $500 \mathrm{mT}$. The influence of the applied magnetic field direction on quality, morphology, and composition of alloy was also determined. In this case, the effect of the composition of the used electrolyte was checked as well.

To check the quality of samples, photos were taken using SEM JEOL-6000 Plus (Tokyo, Japan). The composition of coatings was determined using EDS analysis. The phase composition of alloy was investigated using WD XRF analysis Rigaku Primini (Tokyo, Japan) with palladium source of radiation. The XPS analyses were carried out in a PHI VersaProbeII Scanning XPS system (Chigasaki, Japan) using monochromatic $\mathrm{Al} \mathrm{K} \alpha(1486.6 \mathrm{eV}) \mathrm{X}$-rays focused to a $100 \mu \mathrm{m}$ spot and scanned over the area of $400 \mu \mathrm{m} \times 400 \mu \mathrm{m}$. The photoelectron take-off angle was $45^{\circ}$, and the pass energy in the analyzer was set to $117.50 \mathrm{eV}(0.5 \mathrm{eV}$ step) for survey scans and $46.95 \mathrm{eV}$ ( $0.1 \mathrm{eV}$ step) to obtain highenergy resolution spectra for the $\mathrm{C} 1 \mathrm{~s}, \mathrm{O} 1 \mathrm{~s}, \mathrm{~N} 1 \mathrm{~s}$ and Re 4f regions. A dual-beam charge compensation with $7 \mathrm{eV} \mathrm{Ar}^{+}$ ions and $1 \mathrm{eV}$ electrons were used to maintain a constant sample surface potential regardless of the sample conductivity. All XPS spectra were charge referenced to the unfunctionalized, saturated carbon $(\mathrm{C}-\mathrm{C}) \mathrm{C} 1 \mathrm{~s}$ peak at $285.0 \mathrm{eV}$. The operating pressure in the analytical chamber was less than $3 \times 10^{-7}$ mbar. Deconvolution of spectra was carried out using PHI MultiPak software (v.9.9.0.8). Spectrum background was subtracted using the Shirley method.

\section{Results and discussion}

\subsection{Electrodeposition of Co-Fe alloy cones}

In the field of $\mathrm{Co}-\mathrm{Fe}$ alloy cones electrodeposition by one-step method with crystal modifier, there were no previous works in this field. It was required to find the most appropriate conditions of the process. Firstly, the influence of crystal modifier amount on the conical shape of structures was investigated. The addition of ammonium chloride to electrolyte B was $40 \mathrm{~g} / \mathrm{l}$ and $100 \mathrm{~g} / \mathrm{l}$, respectively. The electrochemical deposition process was carried out at $60^{\circ} \mathrm{C}$, and the value of current density was $20 \mathrm{~mA} / \mathrm{cm}^{2}$. The results are shown in Fig. 2.

It can be noticed that structures are sharp-ended in both cases-however, lower addition of crystal modifier allows obtaining uniform cones. There are several irregularities for a greater amount of $\mathrm{NH}_{4} \mathrm{Cl}$. These structures are also shorter. Usually, there is no information about the amount of used crystal modifier in the literature, especially in the case of $\mathrm{Co}-\mathrm{Fe}$ alloys. However, these two values were chosen based on a literature review connected with the electrodeposition of different metals conical structures $[24,25]$ and own performed research.

Because Co-Fe alloys can be deposited at room temperature [19], the influence of this parameter was also determined. SEM photos of structures obtained at different temperatures are shown in Fig. 3.

Obtained results show that room temperature is too low for the synthesis of conical structures. There are noticeable, small nanocones, but their subsequent growth caused large, round structures. Higher temperature allows obtaining sharp-ended alloy cones. This value was chosen based on previous observations. Electrolyte, which contains an addition of $\mathrm{NH}_{4} \mathrm{Cl}$, is not stable at a lower temperature. This was also confirmed by [24]. It corroborated that the optimal temperature ranges from 60 to $70{ }^{\circ} \mathrm{C}$. Its further increasing caused decomposition of the solution.

Finally, the influence of electrodeposition time on the quality of structures was checked. Based on the results described above, $40 \mathrm{~g} / \mathrm{l} \mathrm{NH}_{4} \mathrm{Cl}$ and $60{ }^{\circ} \mathrm{C}$ were applied as electrodeposition conditions. The electrolyte $\mathrm{B}$ was used. SEM photos of layers are shown in Fig. 4.

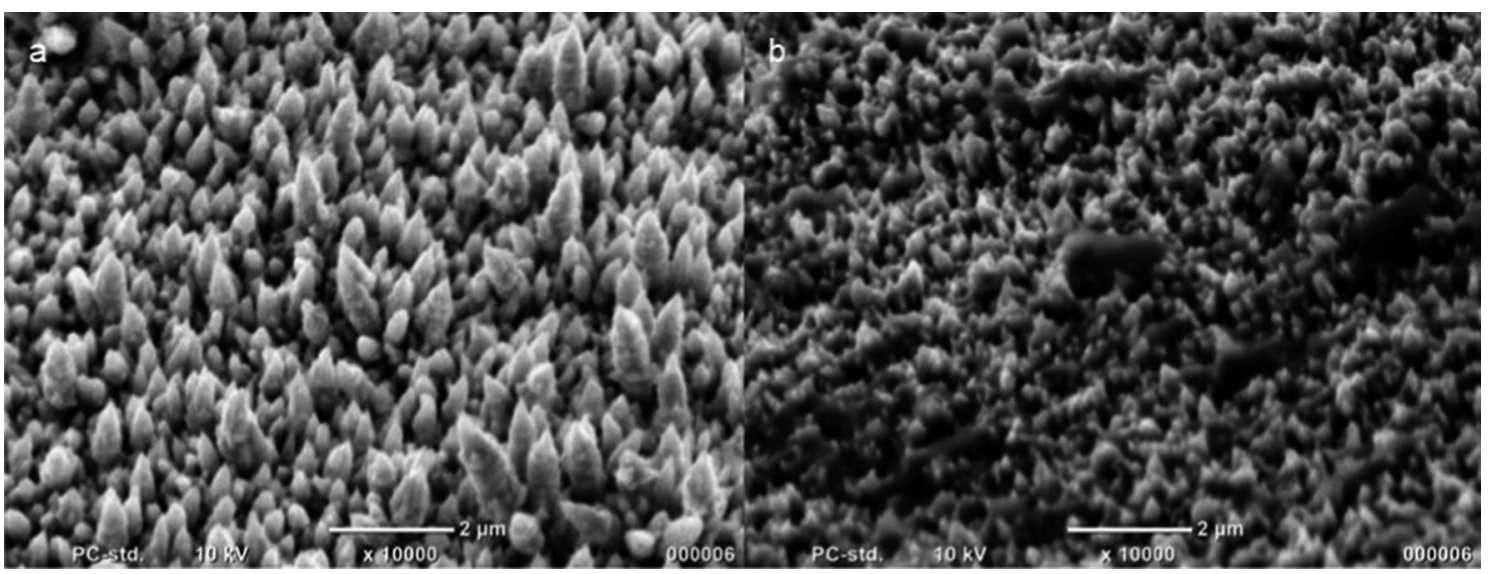

Fig. 2 Co-Fe cones synthesized from the electrolyte containing: a $40 \mathrm{~g} / \mathrm{l}$ and b $100 \mathrm{~g} / 1 \mathrm{NH}_{4} \mathrm{Cl}$ (magnification: $\times 10 \mathrm{k}$ ) 


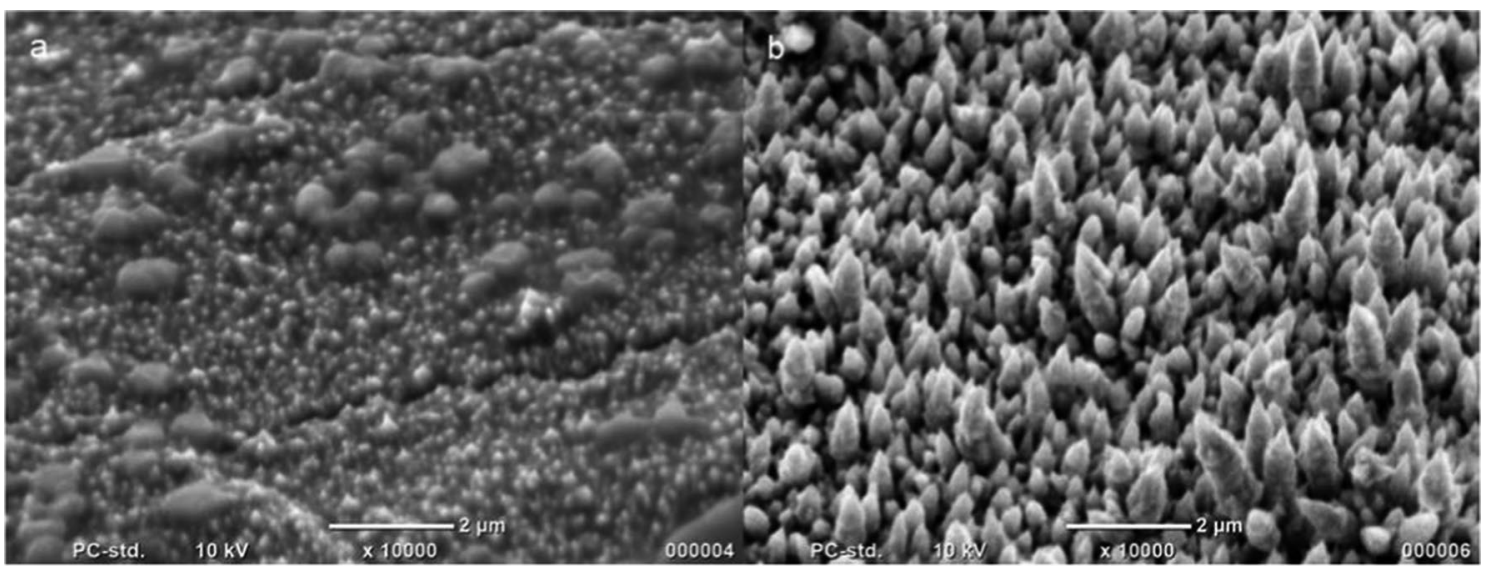

Fig. 3 Co-Fe conical structures fabricated at a room temperature and $\mathbf{b} 60{ }^{\circ} \mathrm{C}$ Electrodeposition conditions: electrolyte $\mathrm{B}, 20 \mathrm{~mA} / \mathrm{cm}^{2}, 10 \mathrm{~min}$ and $40 \mathrm{~g} / 1 \mathrm{NH}_{4} \mathrm{Cl}$ (magnification: $\times 10 \mathrm{k}$ )

It can be noticed that with an increase in time, there is an increase in the size of cones. However, the prolongation of deposition time causes appearing of round structures. It was also confirmed by [24]. Moreover, other applied parameters strongly influenced it. In [24] this time was about tens of seconds. As it was mentioned before, there is no work connected with the synthesis of Co-Fe alloy structures by this method. The critical time of electrodeposition in the case of these alloy cones is $10 \mathrm{~min}$. These structures also show the best quality connected with sharp tips and uniform height.

To confirm obtaining Co-Fe alloy cones, the EDS analysis was performed. The results of the mapping analysis are shown in Fig. 5.

Obtained results show that there is a uniform distribution of $\mathrm{Co}$ and $\mathrm{Fe}$. The presence of chloride connected with the composition of electrolyte was also checked. The chemical composition is as follows: $48.68 \%$ at. $\mathrm{Co}, 46.41 \%$ at. $\mathrm{Fe}$, $4.91 \%$ at. $\mathrm{O}$ and $0 \%$ at. $\mathrm{Cl}$. It can be noticed that there is no present of $\mathrm{Cl}$ from the electrolyte. The amount of $\mathrm{Co}$ and $\mathrm{Fe}$ is almost equal. It is related to the electrolyte composition.

The attempt to add $\mathrm{NaCl}$ instead of $\mathrm{NH}_{4} \mathrm{Cl}$ was made. Sodium chloride was added to the electrolyte $\mathrm{B}$. The samples were electrodeposited at room temperature and $60{ }^{\circ} \mathrm{C}$. The results are shown in Fig. 6.

As it can be noticed, the change of the used crystal modifier allows the synthesis of the covering of the sample surface with the conical structures at higher temperatures. They are characterized by heterogeneous height. The electrodeposition at room temperature was performed due to the stability of the solution in a wide range of temperatures. These results highlight the significant importance of the electrodeposition parameters-the addition of chloride ions which are the crystal modifiers is enough to synthesis cones. The EDS analysis shows that the chemical composition of these coatings is similar. They are following:
$41.09 \%$ at. $\mathrm{Fe}, 53 \%$ at. $\mathrm{Co}, 0.76 \%$ at. $\mathrm{Cl}, 5.15 \%$ at. $\mathrm{O}$ (for the sample obtained at room temperature) and $40.33 \%$ at. $\mathrm{Fe}, 54.33 \%$ at. $\mathrm{Co}, 0.01 \%$ at. $\mathrm{Cl}, 5.33 \%$ at. $\mathrm{O}$ (for the one synthesized at $60{ }^{\circ} \mathrm{C}$ ).

The influence of the electrolyte composition on the cones morphology was analyzed based on SEM photos. The results are shown in Fig. 7.

As it can be noticed, the round-ended structures are electrodeposited only from the electrolyte A. However, in the case of a higher concentration of $\mathrm{FeSO}_{4}$ (electrolyte C), the structures are characterized by sharp tips and similar size. There is a significant difference in the sample surface compositions. EDS results are the following: $24.86 \%$ at. $\mathrm{Fe}, 69.15 \%$ at. $\mathrm{Co}, 0.13 \%$ at. $\mathrm{Cl}, 5.86 \%$ at. $\mathrm{O}$ (electrolyte $\mathrm{A}$ ) and $53.65 \%$ at. $\mathrm{Fe}, 39.23 \%$ at. $\mathrm{Co}, 0 \%$ at. $\mathrm{Cl}, 7.12 \%$ at. $\mathrm{O}$ (electrolyte $\mathrm{C}$ ). These results are connected with the values of the $\mathrm{CoSO}_{4}$ and $\mathrm{FeSO}_{4}$ concentrations in the solutions. Generally, the sharpest-ended and the most uniform cones can be synthesized from electrolyte $C$. Based on the SEM photos, the height of the cones was determined for each coating by measurement the height of 100 cones randomly distributed on the surface. Each cone was measured for 3 times and then the average value was calculated. The results are shown in Fig. 8.

As it can be noticed, the results of the estimation are in agreement with size of the structures shown in Fig. 7. However, these values are approximate due to the dense distribution of structures what prevents accurate measurements from the bottom of the single cone.

Due to the quality of the layer, the following electrodeposition conditions were chosen for application of magnetic field: current density $\mathrm{i}=20 \mathrm{~mA} / \mathrm{cm}^{2}$, temperature $\mathrm{T}=60^{\circ} \mathrm{C}$, time $\mathrm{t}=10 \mathrm{~min}$ and the addition of $\mathrm{NH}_{4} \mathrm{Cl}$ : $40 \mathrm{~g} / 1$. 


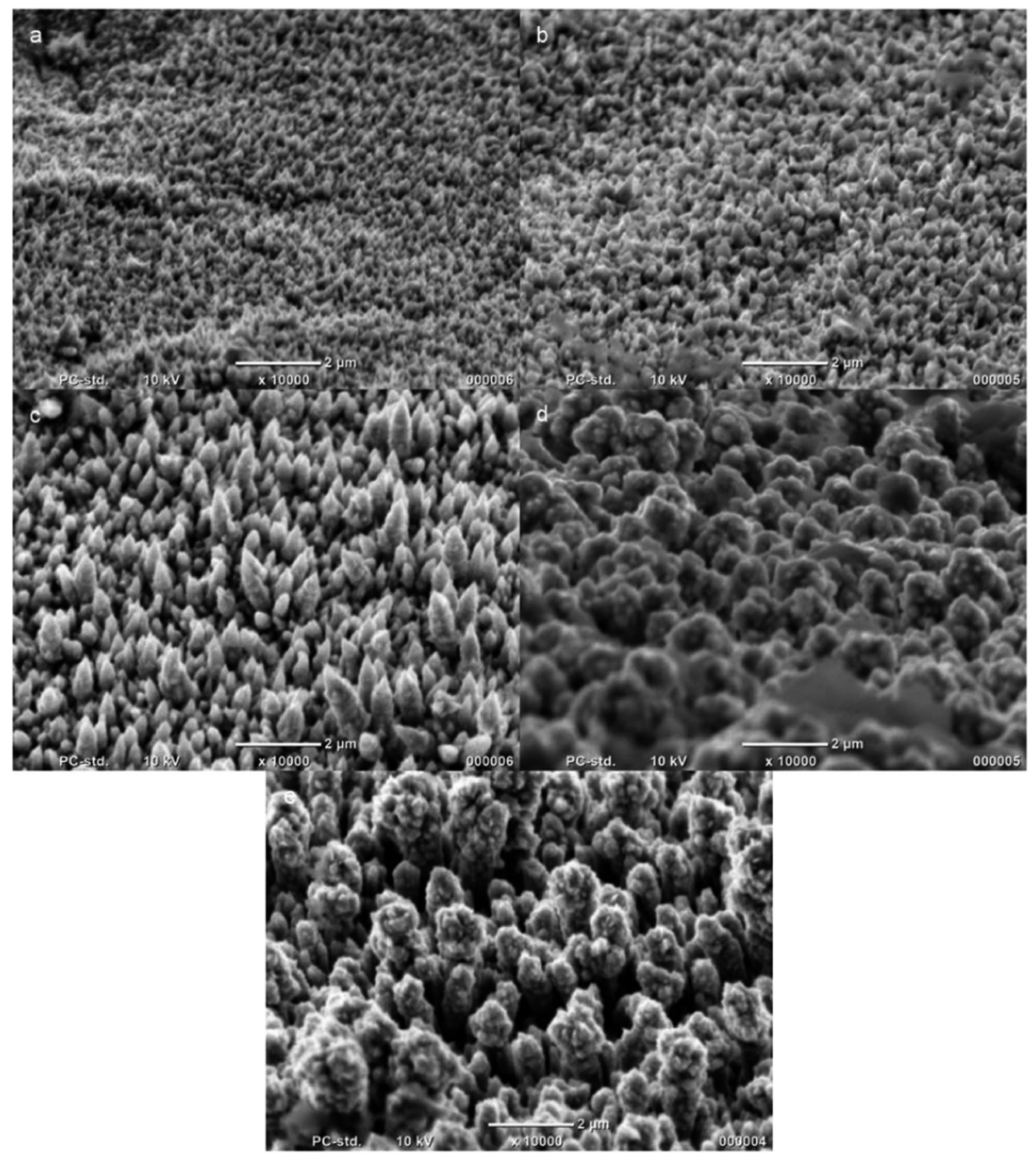

Fig. 4 Time of electrodeposition: a $5 \mathrm{~min}, \mathbf{b} 8 \mathrm{~min}, \mathbf{c} 10 \mathrm{~min}, \mathbf{d} 16 \mathrm{~min}$ and e $20 \mathrm{~min}$ (magnification: $\times 10 \mathrm{k}$ )

\subsection{Electrodeposition with applied magnetic field}

With regard to the ferromagnetic character of $\mathrm{Co}$ and $\mathrm{Fe}$, the superimposed magnetic field was applied during electrodeposition. The changes in alloys morphology and composition could be expected. The influence of magnetic field direction (parallel and perpendicular) and intensity $(250 \mathrm{mT}$ and 500 $\mathrm{mT}$ ) on the samples produced from the different electrolytes was investigated. SEM photos are shown in Fig. 9.

The influence of the magnetic field on the morphology of coatings is noticeable. However, the conical structures cannot be synthesized from all used electrolytes in all cases. For structures electrodeposited from the electrolyte A, cones obtained in a parallel magnetic field are smaller but sharpended. The perpendicular magnetic field increases the uniformity of their size. For solutions B, round-ended structures are produced in the parallel magnetic field. They are also smaller but more homogenous than those synthesized under the perpendicular magnetic field. There is no significant difference between the surface of the samples electrodeposited from the electrolyte $\mathrm{C}$. In both cases, small, uniform cones with sharp tips grow. 

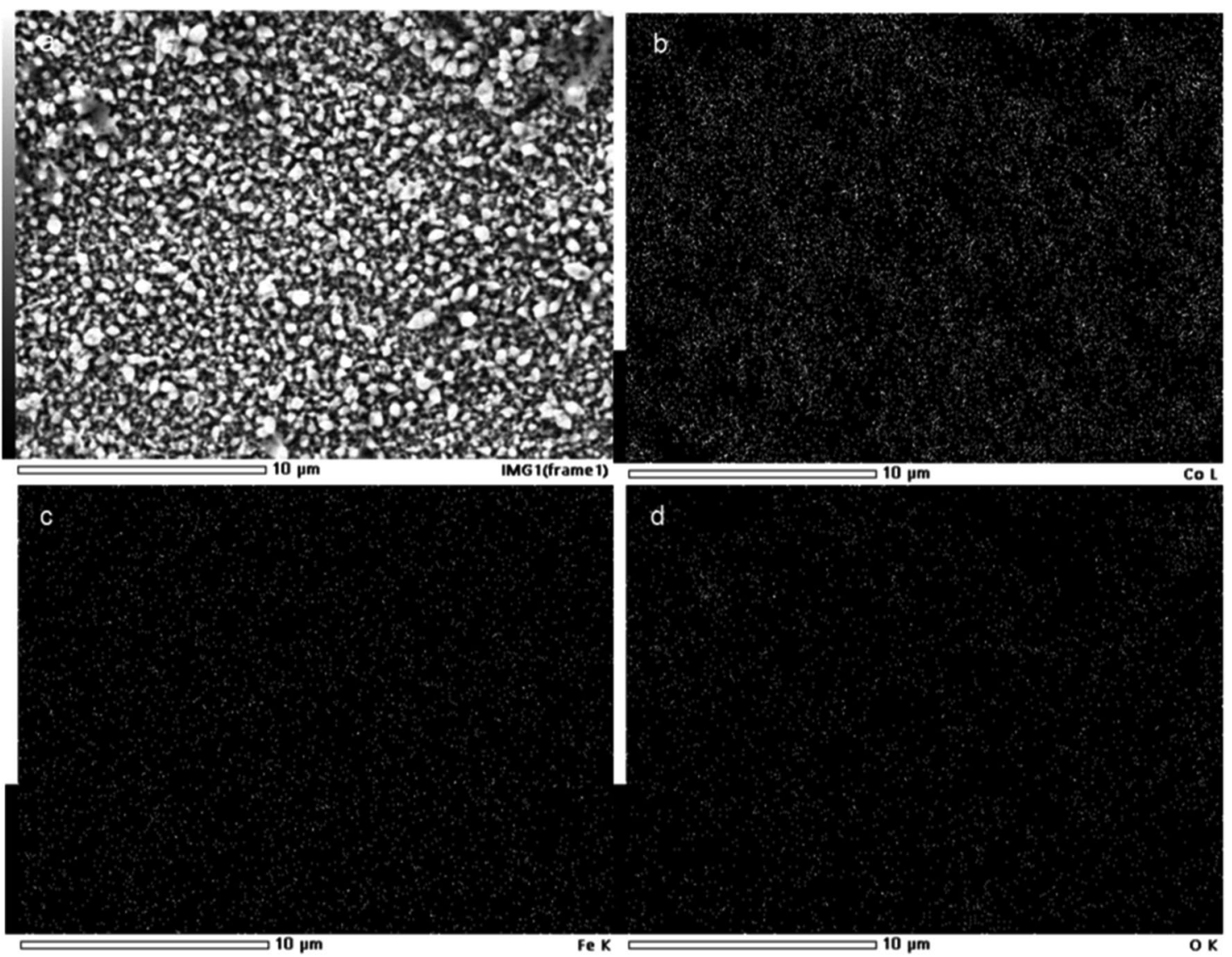

Fig. 5 Mapping analysis of Co-Fe cones: a top view of the surface and distribution of: $\mathbf{b} \mathrm{Co}, \mathbf{c} \mathrm{Fe}$ and $\mathbf{d}$ O. Electrodeposition conditions: $\mathrm{i}$ $=20 \mathrm{~mA} / \mathrm{cm}^{2}, \mathrm{~T}=60^{\circ} \mathrm{C}, \mathrm{t}=10 \mathrm{~min}$ and $40 \mathrm{~g} / 1 \mathrm{NH}_{4} \mathrm{Cl}$

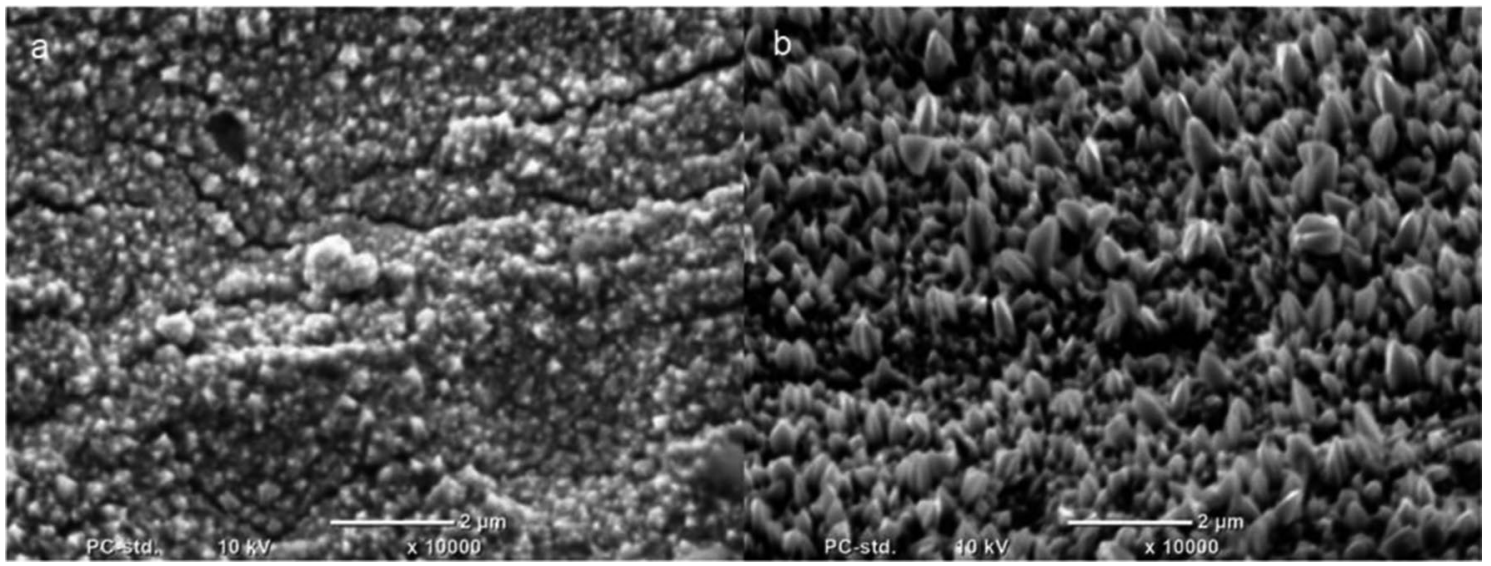

Fig. $6 \mathrm{Co}-\mathrm{Fe}$ conical structures fabricated from the electrolyte containing $\mathrm{NaCl}$ at $\mathbf{a}$ room temperature and b) $60{ }^{\circ} \mathrm{C}$. Electrodeposition conditions: $20 \mathrm{~mA} / \mathrm{cm}^{2}, 10 \mathrm{~min}$ and $40 \mathrm{~g} / 1 \mathrm{NH}_{4} \mathrm{Cl}$ (magnification: $\times 10 \mathrm{k}$ )

EDS analysis was performed to check the dependency between applied magnetic field and the chemical compositions of obtained alloys. The results are shown in Table 2.
It can be noticed that or both directions of the magnetic field, $\mathrm{Co}-\mathrm{Fe}$ alloys are obtained from all the electrolytes. Application of magnetic field does not change the relation 


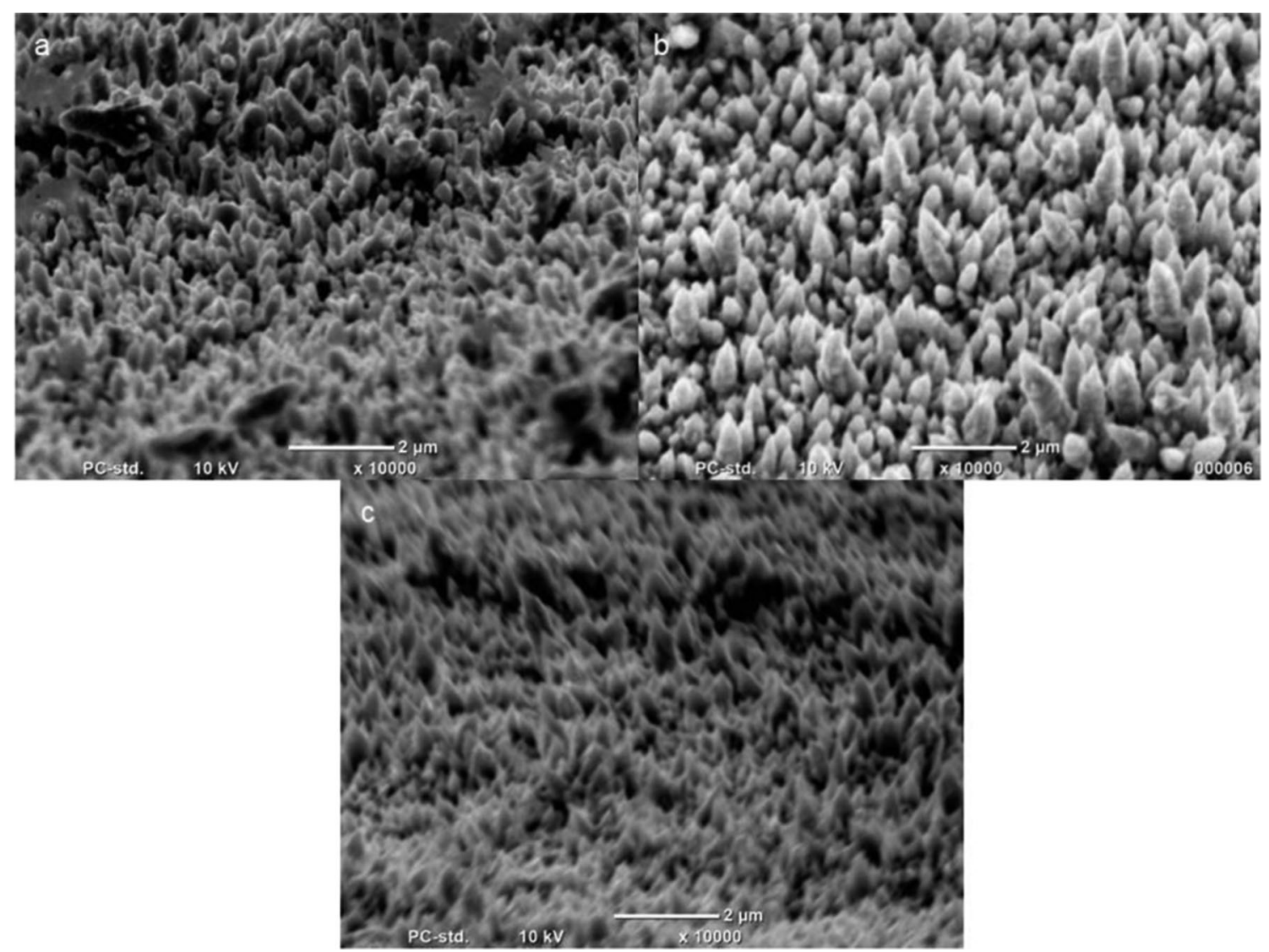

Fig. 7 Co-Fe conical structures fabricated from the electrolyte a A, b B and c C. Electrodeposition conditions: $20 \mathrm{~mA} / \mathrm{cm}^{2}, 10 \mathrm{~min}, 60{ }^{\circ} \mathrm{C}$, and $40 \mathrm{~g} / 1 \mathrm{NH}_{4} \mathrm{Cl}$ (magnification: $\times 10 \mathrm{k}$ )

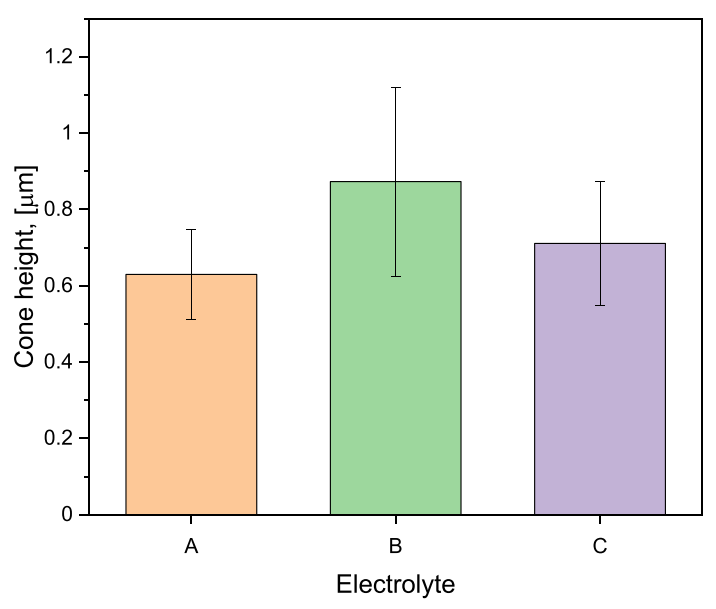

Fig. 8 Average height of cones synthesized from electrolyte A, B and $\mathrm{C}$ determined based on SEM photos

between the concentration of $\mathrm{Co}$ and $\mathrm{Fe}$ in the electrolytes and their amount in the coating. There is a noticeable difference in the amount between $\mathrm{Co}$ and $\mathrm{Fe}$ in relation to their addition to the solution. The chloride appears only for the sample obtained from electrolyte $\mathrm{C}$ in a perpendicular magnetic field. In this case, there is also a high content of oxygen. Besides this sample, the detected amount of $\mathrm{Cl}$ is below the device detection level and can be omitted. The presence of $\mathrm{Cu}$ is connected with the used substrate. However, the electrodeposition of any of $\mathrm{Co}$ or $\mathrm{Fe}$ is not clearly promoted by any of the magnetic field directions.

The sample surfaces synthesized from the electrolyte B were analyzed using XPS as well. The spectra are shown in Fig. 10.

Unfortunately, the Al lamp used in this analysis does not allow to recognize lines from Fe ions. The multiplet splitting structure characteristic for first-row transition metal species containing unpaired electrons is shown in both cases. The Co $2 p_{3 / 2}$ spectra are similar as well. Based on [26-28], it was determined that there are three states of cobalt on the sample surfaces. The first peak centred at $778.1 \mathrm{eV}$ is connected with metallic Co. The lines at 780 and $781 \mathrm{eV}$ and $782-778 \mathrm{eV}$ point out that $\mathrm{Co}$ is in two oxidation states: $\mathrm{Co}^{3+}$ and $\mathrm{Co}^{2+}$ oxidation states and can be connected with the presence of $\mathrm{Co}_{3} \mathrm{O}_{4}$ and $\mathrm{CoO}$. The relative concentrations of cobalt species present in analyzed samples are shown in Table 3. 


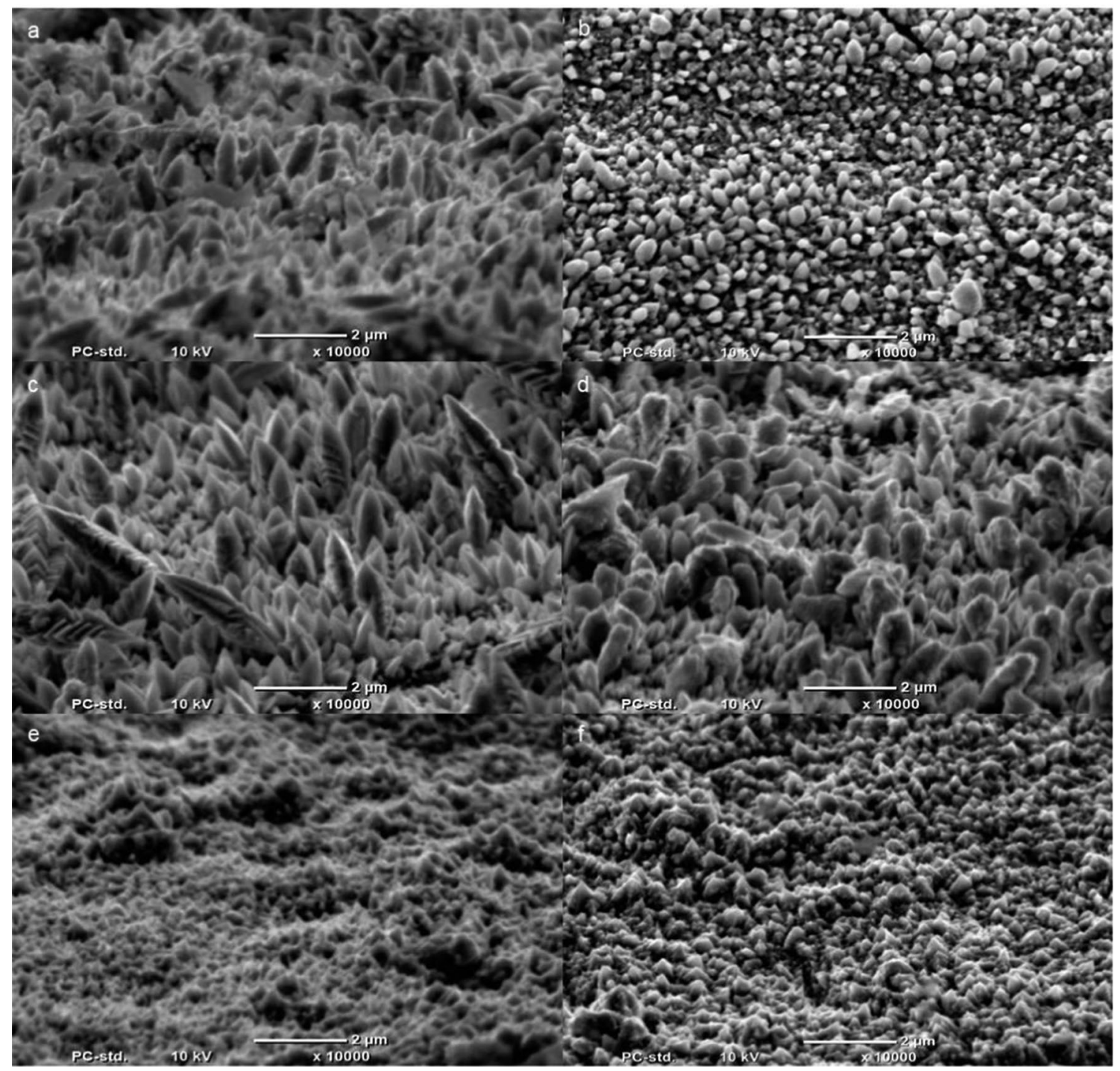

Fig. 9 Coating obtained at $500 \mathrm{mT}$ in $(\mathbf{a}, \mathbf{c}, \mathbf{e})$ perpendicular and $(\mathbf{b}, \mathbf{d}, \mathbf{f})$ parallel magnetic field (magnification: $\times 10 \mathrm{k})$ from the electrolyte: A $(\mathbf{a}, \mathbf{b}), \mathrm{B}(\mathbf{c}, \mathbf{d})$, and $\mathrm{C}(\mathbf{e}, \mathbf{f})$

These results confirm that on the sample surfaces, there are cobalt oxides. Their presence is essential in the case of the sample application as catalysts. These oxides are responsible for the electrocatalytic properties of samples. Both surfaces are a mixture of metallic cobalt and its different oxide states.

To check if there is any change in the crystal system of the alloy, the XRD analysis was performed. The sample electrodeposited from electrolyte B was chosen. The results are shown in Fig. 11.

In the presence of a magnetic field, two new peaks appear. They are combined with $\mathrm{Co}-\mathrm{Fe}$ alloy. However, other peaks can be identified as $\mathrm{Cu}$ (the substrate) or $\mathrm{Co}-\mathrm{Fe}$ ones. They cannot be distinguished due to the small mass of coatings. The peaks from $\mathrm{Cu}$ substrate appear due to the thinness of coatings.

\section{Conclusions}

Performed experiments and obtained results confirm that the synthesis of conical $\mathrm{Co}-\mathrm{Fe}$ alloy structures by one-step method is possible. However, there is a dependency between the added amount of $\mathrm{NH}_{4} \mathrm{Cl}$ and the morphology of obtained structures. Its greater addition causes the formation of many irregularities. Additionally, solution heating is required. The electrolyte is not stable at a temperature below $60^{\circ} \mathrm{C}$. The duration of the process is limited to $10 \mathrm{~min}$. Its prolongation 
Table 2 Chemical composition of obtained alloys

\begin{tabular}{|c|c|c|c|}
\hline Electrolyte & $\begin{array}{l}\text { Direction of magnetic } \\
\text { field }\end{array}$ & Element & $\%$ at \\
\hline \multirow[t]{8}{*}{ A } & \multirow[t]{4}{*}{ Perpendicular } & $\mathrm{Fe}$ & 26.82 \\
\hline & & Co & 67.72 \\
\hline & & $\mathrm{Cl}$ & 0.01 \\
\hline & & $\mathrm{O}$ & 5.46 \\
\hline & \multirow[t]{4}{*}{ Parallel } & $\mathrm{Fe}$ & 24.38 \\
\hline & & Co & 69.74 \\
\hline & & $\mathrm{Cl}$ & 0.06 \\
\hline & & $\mathrm{O}$ & 5.83 \\
\hline \multirow[t]{8}{*}{ B } & \multirow[t]{4}{*}{ Perpendicular } & $\mathrm{Fe}$ & 43.38 \\
\hline & & Co & 52.70 \\
\hline & & $\mathrm{Cl}$ & 0.01 \\
\hline & & $\mathrm{O}$ & 3.91 \\
\hline & \multirow[t]{4}{*}{ Parallel } & $\mathrm{Fe}$ & 43.29 \\
\hline & & Co & 49.04 \\
\hline & & $\mathrm{Cl}$ & 0.56 \\
\hline & & $\mathrm{O}$ & 7.10 \\
\hline \multirow[t]{8}{*}{$\mathrm{C}$} & \multirow[t]{4}{*}{ Perpendicular } & $\mathrm{Fe}$ & 44.63 \\
\hline & & Co & 31.96 \\
\hline & & $\mathrm{Cl}$ & 2.45 \\
\hline & & $\mathrm{O}$ & 20.97 \\
\hline & \multirow[t]{4}{*}{ Parallel } & $\mathrm{Fe}$ & 50.82 \\
\hline & & Co & 36.35 \\
\hline & & $\mathrm{Cl}$ & - \\
\hline & & $\mathrm{O}$ & 12.83 \\
\hline
\end{tabular}

changes the shape for round one. The change of the crystal modifier for $\mathrm{NaCl}$ allows the successful synthesis of the cones but still at higher temperatures. Application of the different electrolytes causes an increase in the quality of the cone in the case of electrolyte C.

Due to the magnetic properties of $\mathrm{Co}$ and $\mathrm{Fe}$, the expected strong influence of the applied magnetic field on coating morphology appears. The influence of the magnetic field on the morphology of coatings is noticeable. However, the conical structures cannot be synthesized from all used electrolytes in all cases. There are no significant differences between the structures produced from electrolyte C. Moreover, there is a noticeable relationship between the amount of $\mathrm{Co}$ and $\mathrm{Fe}$ on the sample surfaces and their addition to the solution. But the electrodeposition of any of $\mathrm{Co}$ or $\mathrm{Fe}$ is not clearly promoted by any of the magnetic field directions. The presence of cobalt oxides is confirmed by XPS analysis. They are related to the electrocatalytic properties of structures in water-splitting reactions and can be connected with future studies on the application as catalysts. Moreover XRD analysis confirms the synthesis of Co-Fe alloys. Two new peaks appear in the case of the applied magnetic field. Due to the thinness of the coatings, it is impossible to distinguish if they are connected with the copper substrate or the alloy. The conical shape of the obtained structures can enhance the superhydrophobic properties of the samples. However, this issue needs to be confirmed by further experiments.
Fig. 10 XPS spectra of sample synthesized a without and $\mathbf{b}$ with the perpendicular magnetic field $(500 \mathrm{mT})$ (a)

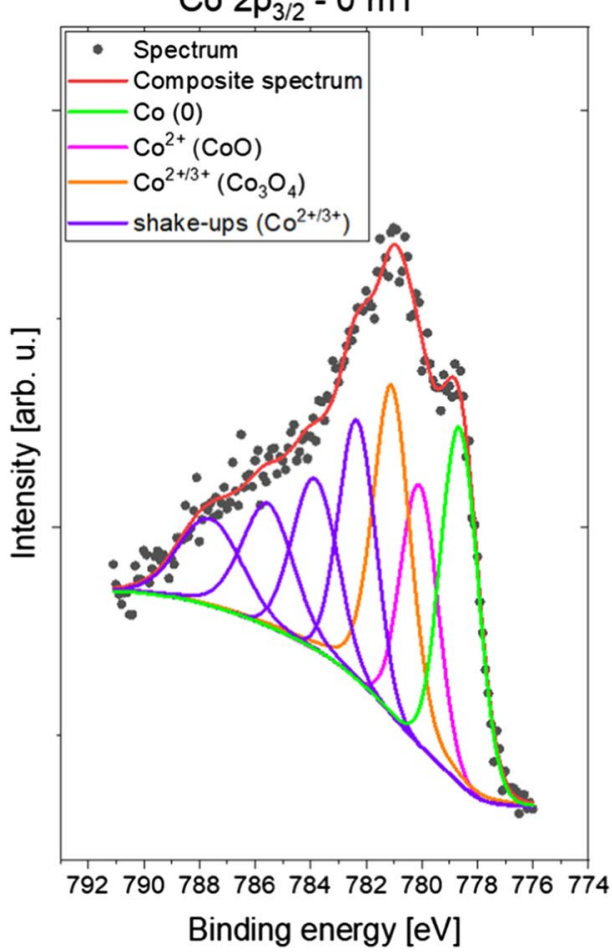

(b)

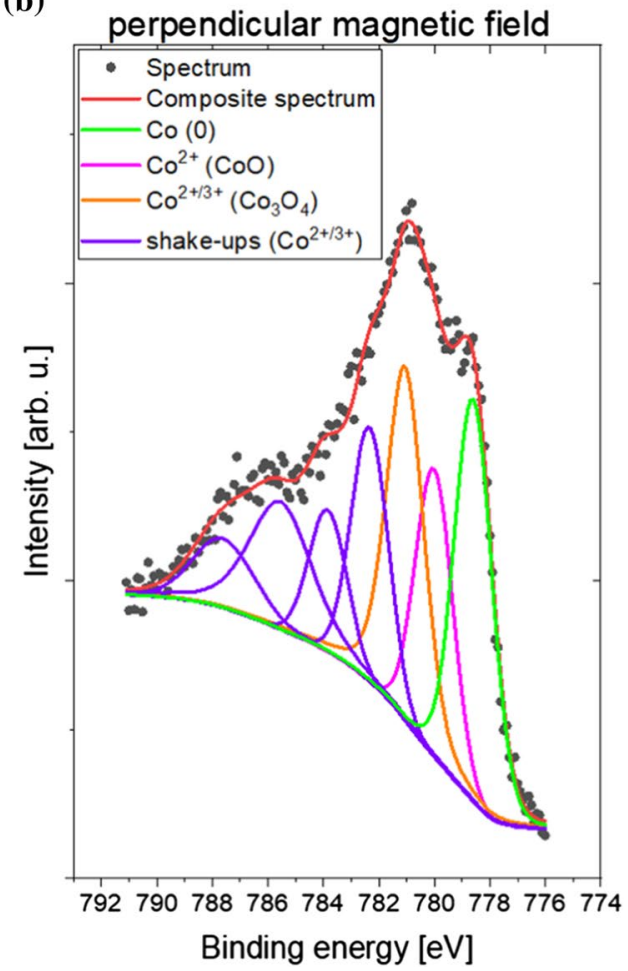


Table 3 Relative concentrations of cobalt species present in analyzed samples

\begin{tabular}{llll}
\hline Sample & $\mathrm{Co}(0)$ & $\mathrm{CoO}$ & $\mathrm{Co}_{3} \mathrm{O}_{4}$ \\
\hline $0 \mathrm{mT}$ & 20.0 & 36.8 & 43.2 \\
$\begin{array}{l}500 \mathrm{mT}, \text { perpendicular } \\
\text { magnetic field }\end{array}$ & 22.6 & 35.6 & 41.8 \\
\hline
\end{tabular}

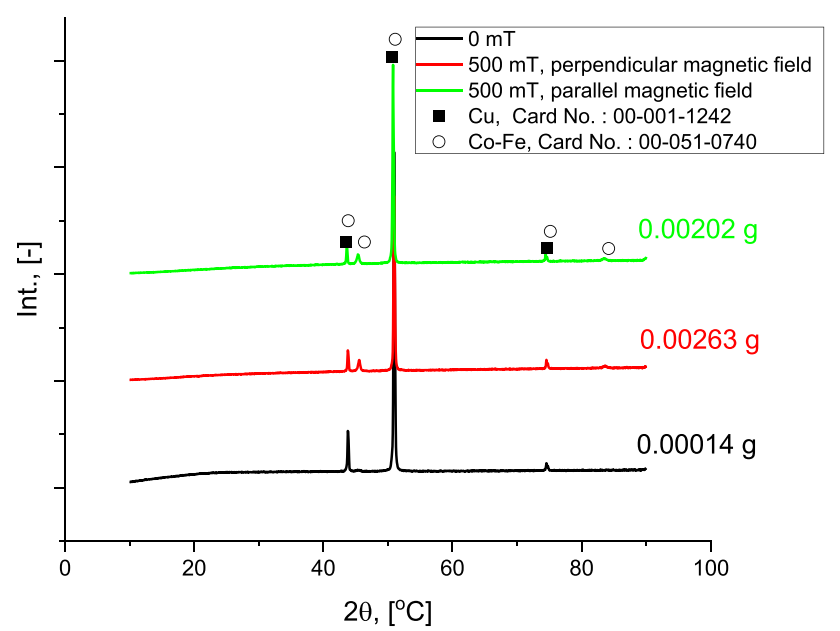

Fig. 11 XRD analysis of obtained coatings with the marked mass of the coatings and crystalline size

Funding This study was funded by The National Science Centre (grant number UMO2016/23/G/ST5/04058).

Availability of data and materials Authors can confirm that all relevant data are included in the article.

\section{Declarations}

Conflict of interest Katarzyna Skibińska declares that she has no conflict of interest. Dawid Kutyła declares that he has no conflict of interest. Karolina Kołczyk-Siedlecka declares that she has no conflict of interest. Mateusz M. Marzec declares that he has no conflict of interest. Remigiusz Kowalik declares that he has no conflict of interest. Piotr Żabiński declares that he has no conflict of interest.

Ethical approval This article does not contain any studies with human participants performed by any of the authors.

Open Access This article is licensed under a Creative Commons Attribution 4.0 International License, which permits use, sharing, adaptation, distribution and reproduction in any medium or format, as long as you give appropriate credit to the original author(s) and the source, provide a link to the Creative Commons licence, and indicate if changes were made. The images or other third party material in this article are included in the article's Creative Commons licence, unless indicated otherwise in a credit line to the material. If material is not included in the article's Creative Commons licence and your intended use is not permitted by statutory regulation or exceeds the permitted use, you will need to obtain permission directly from the copyright holder. To view a copy of this licence, visit http://creativecommons.org/licenses/by/4.0/.

\section{References}

1. Luborsky FE, Livingston JD, Chin GY. Magnetic properties of metals and alloys. In: Physical Metallurgy. North-Holland: Elsevier; 1996. pp. 2501-2565.

2. Yamaura S. Microstructure and magnetostriction of heavily groove-rolled Fe-Co alloy wires. Mater Sci Eng B Solid-State Mater Adv Technol. 2021. https://doi.org/10.1016/j.mseb.2020. 114946.

3. Wang Z, Zhang S, Lv X, Bai J, Yu W, Liu J. Electrocatalytic hydrogen evolution on iron-cobalt nanoparticles encapsulated in nitrogenated carbon nanotube. Int J Hydrogen Energy. 2019. https://doi.org/10.1016/j.ijhydene.2019.04.235.

4. Chen Z, Yang X, Fu Y. Influence of sodium propargyl sulfonate on electrodeposition of Fe-Co alloy. J Alloys Compd. 2020. https://doi.org/10.1016/j.jallcom.2020.154167.

5. Chotibhawaris T, Tachai L, Jantaratana P, Boonyongmaneerat Y. Influence of the electrodeposited Co-Fe Alloys' characteristics on their magnetic properties. Adv Mater Res. 2014. https://doi. org/10.4028/www.scientific.net/AMR.1025-1026.709

6. Dobosz I, Gumowska W, Czapkiewicz M. Magnetic properties of Co-Fe nanowires electrodeposited in pores of alumina membrane. Arch Metall Mater. 2013. https://doi.org/10.2478/ amm-2013-0052.

7. Vock S, Tschulik K, Uhlemann M, Hengst C, Fähler S, Schultz L, Neu V. Magnetostatic nearest neighbor interactions in a $\mathrm{Co}_{48} \mathrm{Fe}_{52}$ nanowire array probed by in-field magnetic force microscopy. J Appl Phys. 2015. https://doi.org/10.1063/1.49372 75 .

8. Vock S, Hengst C, Wolf M, Tschulik K, Uhlemann M, Sasvári Z, Makarov D, Schmidt OG, Schultz L, Neu V. Magnetic vortex observation in $\mathrm{FeCo}$ nanowires by quantitative magnetic force microscopy. Appl Phys Lett. 2014. https://doi.org/10.1063/1. 4900998.

9. Lallemand F, Ricq L, Deschaseaux E, De Vettor L, Berçot P. Electrodeposition of cobalt-iron alloys in pulsed current from electrolytes containing organic additives. Surf Coat Technol. 2005. https://doi.org/10.1016/j.surfcoat.2005.01.038.

10. Chansena A, Sutthiruangwong S. Corrosion behavior of electrodeposited Co-Fe alloys in aerated solutions. J Magn Magn Mater. 2017. https://doi.org/10.1016/j.jmmm.2017.01.044.

11. Hashemzadeh M, Raeissi K, Ashrafizadeh F, Khorsand S. Effect of ammonium chloride on microstructure, super-hydrophobicity and corrosion resistance of nickel coatings. Surf Coatings Technol. 2015. https://doi.org/10.1016/j.surfcoat.2015.11.008.

12. Lee JM, Jung KK, Lee SH, Ko JS. One-step fabrication of nickel nanocones by electrodeposition using $\mathrm{CaCl} 2 \cdot 2 \mathrm{H} 2 \mathrm{O}$ as capping reagent. Appl Surf Sci. 2016. https://doi.org/10.1016/j.apsusc. 2016.02.006.

13. Tian F, Hu A, Li M, Mao D. Superhydrophobic nickel films fabricated by electro and electroless deposition. Appl Surf Sci. 2012. https://doi.org/10.1016/j.apsusc.2011.11.130.

14. Xu N, Sarkar DK, Chen XG, Tong WP. Corrosion performance of superhydrophobic nickel stearate/nickel hydroxide thin films on aluminum alloy by a simple one-step electrodeposition process. Surf Coatings Technol. 2016. https://doi.org/10.1016/j.surfcoat. 2016.05.050.

15. Zhang X, Wang L, Levänen E. Superhydrophobic surfaces for the reduction of bacterial adhesion. RSC Adv. 2013. https://doi.org/ $10.1039 / \mathrm{c} 3 \mathrm{ra} 40497 \mathrm{~h}$. 
16. Gregory TS, Cheng R, Tang G, Mao L, Tsz Z, Tse H. The magnetohydrodynamic effect and its associated material designs for biomedical applications: a state-of-the-art review. Adv Funct Mater. 2016. https://doi.org/10.1002/adfm.201504198.

17. Tacken RA, Janssen LJJ. Applications of magnetoelectrolysis. J Appl Electrochem. 1995. https://doi.org/10.1007/BF00251257.

18. Osaka T, Asahi T, Kawaji J, Yokoshima T. Development of highperformance magnetic thin film for high-density magnetic recording. Electrochim Acta. 2005. https://doi.org/10.1016/j.electacta. 2004.10.099.

19. Koza JA, Karnbach F, Uhlemann M, McCord J, Mickel C, Gebert A, Baunack S, Schultz L. Electrocrystallisation of CoFe alloys under the influence of external homogeneous magnetic fieldsProperties of deposited thin films. Electrochim Acta. 2010. https:// doi.org/10.1016/j.electacta.2009.08.069.

20. Kołodziejczyk K, Miękoś E, Zieliński M, Jaksender M, Szczukocki D, Czarny K, Krawczyk B. Influence of constant magnetic field on electrodeposition of metals, alloys, conductive polymers, and organic reactions. J Solid State Electrochem. 2018;22:162974. https://doi.org/10.1007/s10008-017-3875-x.

21. Koza JA, Uhlemann M, Gebert A, Schultz L. The effect of magnetic fields on the electrodeposition of $\mathrm{CoFe}$ alloys. Electrochim Acta. 2008. https://doi.org/10.1016/j.electacta.2008.02.082.

22. Karnbach F, Uhlemann M, Gebert A, Eckert J, Tschulik K. Magnetic field templated patterning of the soft magnetic alloy $\mathrm{CoFe}$. Electrochim Acta. 2014. https://doi.org/10.1016/j.electacta.2014. 01.055 .

23. Koza JA, Uhlemann M, Gebert A, Schultz L. The effect of a magnetic field on the $\mathrm{pH}$ value in front of the electrode surface during the electrodeposition of $\mathrm{Co}, \mathrm{Fe}$ and $\mathrm{CoFe}$ alloys. J Electroanal Chem. 2008. https://doi.org/10.1016/j.jelechem.2008.02.009.

24. Hang T, Hu A, Li M, Mao D. Structural control of a cobalt nanocone array grown by directional electrodeposition. CrystEngComm. 2010. https://doi.org/10.1039/b922875f.

25. Rahimi S, Shahrokhian S, Hosseini H. Ternary nickel cobalt iron sulfides ultrathin nanosheets grown on 3-D nickel nanocone arrays-nickel plate current collector as a binder free electrode for fabrication of highly performance supercapacitors. J Electroanal Chem. 2018. https://doi.org/10.1016/j.jelechem.2018.01.004.

26. Biesinger MC, Payne BP, Grosvenor AP, Lau LWM, Gerson AR, Smart RSC. Resolving surface chemical states in XPS analysis of first row transition metals, oxides and hydroxides: $\mathrm{Cr}, \mathrm{Mn}, \mathrm{Fe}$, Co and Ni. Appl Surf Sci. 2011. https://doi.org/10.1016/j.apsusc. 2010.10.051.

27. Okamoto Y, Adachi T, Maezawa A, Imanaka T. Effect of ZnO addition on cobalt-alumina interaction species. Bull Chem Soc Jpn. 1991. https://doi.org/10.1246/bcsj.64.236.

28. Dash KC, Folkesson B, Larsson R, Mohapatra M. An XPS investigation on a series of schiff base dioxime ligands and cobalt complexes. J Electron Spectros Relat Phenomena. 1989. https://doi. org/10.1016/0368-2048(89)85022-4.

Publisher's Note Springer Nature remains neutral with regard to jurisdictional claims in published maps and institutional affiliations. 